\title{
REGULAÇÃO ECONÔMICA ESTATAL: A ANÁLISE DE IMPACTO REGULATÓRIO (AIR) COMO INSTRUMENTO DE AVALIAÇÃO DA EFICIÊNCIA
}

\author{
Ricardo dos Santos Caçapietra ${ }^{1}$ \\ Ana Amélia Barros Miranda ${ }^{2}$
}

\section{RESUMO}

O objetivo deste artigo é verificar a importância da Análise de Impacto Regulatório (AIR) sobre a política regulatória brasileira. Metodologicamente, a abordagem é qualitativa e pautase numa revisão bibliográfica. Trata da eficiência da regulação estatal, a partir do referencial teórico da Análise Econômica do Direito (AED), como fator relevante para a defesa e o incentivo à concorrência, à inovação e ao desenvolvimento econômico.

Palavras-chave: Intervenção estatal na economia; Política regulatória; Análise Econômica do Direito; Análise de impacto regulatório; Eficiência.

\section{STATE ECONOMIC REGULATION: THE REGULATORY IMPACT ANALYSIS (RIA) AS AN EFFICIENCY EVALUATION INSTRUMENT}

\begin{abstract}
The purpose of this article is to verify the importance of the Regulatory Impact Analysis (RIA) on Brazilian regulatory policy. Methodologically, the approach is qualitative and is based on a bibliographic review. It deals with the efficiency of state regulation, based on the theoretical reference of the Economic Analysis of Law (EAL), as a relevant factor for the defense and incentive to competition, innovation and economic development.
\end{abstract}

Keywords: State intervention in the economy; Regulatory policy; Economic Analysis of the Law; Regulatory impact analysis; Efficiency.

\section{INTRODUÇÃO}

A globalização reduziu as distâncias comerciais entre os países, aumentando exponencialmente os mercados para os produtos brasileiros. Por outro lado, a diminuição das barreiras comerciais também expôs no ambiente externo à falta de competitividade das empresas nacionais que, num cenário de baixa produtividade e de regulação econômica

\footnotetext{
${ }^{1}$ Delegado de Polícia Civil, especialista em Sociedade e Gestão de Segurança Pública (UFPA), especialista em Gestão Pública, com ênfase em Políticas Públicas e Governança (EGPA), professor de Gestão Estratégica da Informação (IESP), mestrando em Direito, Políticas Públicas e Desenvolvimento Regional (CESUPA). E-mail: ricardocasapietra@hotmail.com

${ }^{2}$ Advogada, mestre em Direito do Estado pela Universidade da Amazônia (UNAMA), professora de Direito Administrativo (CESUPA). E-mail: ana.amelia@mirandaecastro.adv.br
} 
estatal, tem contabilizado prejuízos no competitivo mercado econômico e financeiro internacional.

Diante disso, a política regulatória, uma das mais tradicionais formas de intervenção estatal nos interesses privados, assume protagonismo no estabelecimento de normas que tenham por objetivo, de maneira simples e objetiva, regular o ambiente de atuação desses agentes econômicos, de forma que o cenário de negócios seja atrativo para investimentos e também para o necessário desenvolvimento de uma perspectiva competitiva e concorrencial por parte do empresariado nacional, beneficiando diretamente usuários de serviços públicos e consumidores.

A partir da década de 90, com o Plano Diretor de Reforma do Aparelho do Estado (PDRE), o Estado brasileiro assumiu um papel coordenador-regulador no campo da economia, em contraposição à intensa exploração de atividades privadas e a direta prestação de serviços públicos, que marcaram no passado recente a atividade estatal.

No âmbito desse espaço de transição, buscou-se inserir o país, até então adepto da administração pública burocrática, definida por controles rígidos formais, num cenário constituído por ações públicas orientadas para resultados, monitoradas por indicadores e metas, relacionadas com a contemporânea administração pública gerencial.

O direito de regulação é disciplina recente no âmbito jurídico brasileiro, que só com o PDRE passou a ser objeto de profunda investigação. Ao contrário dos Estados Unidos, que realizaram importantes reformas com vistas não apenas a modernizar as suas legislações internas, mas principalmente mensurar os impactos desse processo a partir de uma leitura sobre os custos e os benefícios das mudanças propostas, o Brasil não abordou de maneira sistemática a regulação estatal, permanecendo a mercê de um emaranhado normativo, muitas das vezes conflitante entre si, que prejudica o ambiente de negócios e, por conseguinte, a concorrência, a inovação e o desenvolvimento econômico.

Nesse diapasão, não podemos olvidar que desde 1996 a maior parte dos integrantes da Organização para Economia, Cooperação e Desenvolvimento (OCDE) adotaram a Análise de Impacto Regulatório (AIR) como instrumento para melhoraria da eficiência dos regulamentos expedidos por esses países. Trata-se de um instrumento de aperfeiçoamento da eficácia e da eficiência da atividade regulatória, um conjunto de recomendações de procedimentos a serem adotados para orientar a tomada de decisão em regulação, que auxilia o regulador a focar nos ditames legais desta (SALGADO, 2010). 
Desta forma, motivado por uma necessária eficiência no campo da regulamentação estatal, este artigo busca ratificar a necessidade de institucionalização, no ordenamento jurídico brasileiro, da Análise de Impacto Regulatório (AIR) como ferramenta para avaliar o design, o planejamento, a execução e as consequências das políticas regulatórias, ou até mesmo propor medidas desregulatórias, diminuindo tanto as "falhas de mercado" como as "falhas de governo", impactando diretamente nas estratégias do país com relação ao desenvolvimento econômico fundado na proteção e ampliação da concorrência e da constante inovação. A pesquisa é bibliográfica e de abordagem qualitativa, sendo a análise sob uma perspectiva jurídica consequencialista, decorrente da visão pragmática do direito representada pela metodologia e filosofia da AED.

Para isso, será abordada sucintamente a teoria geral da regulação, destacando as principais correntes teóricas, bem como o surgimento, nos Estados Unidos, da forma moderna de agência reguladora. Analisaremos o processo de regulação no Brasil e o papel das respectivas agências reguladoras, para então compreendermos o conceito de eficiência, a partir da lógica da Análise Econômica do Direito (AED), defendendo a necessidade de institucionalização da Análise de Impacto Regulatório (AIR).

\section{TEORIA GERAL DA REGULAÇÃO ECONÔMICA}

Para uma compreensão sistemática do papel da regulação na proteção e incentivo à concorrência e respectivos benefícios a usuários e consumidores, convém destacarmos as principais correntes de pensamento que abordam a política regulatória, partindo de uma análise da perspectiva norte-americana, a saber: teoria do interesse público; e a teoria econômica da regulação.

A denominada escola do interesse público aborda a regulação estatal sob a justificativa da satisfação do interesse público ou do bem comum. Essa teoria apresenta dois pressupostos básicos. Primeiramente, os mercados são frágeis e funcionariam de maneira bem ineficiente. Em segundo lugar, a regulação estatal seria um processo perfeito, praticamente sem custos.

Esse arcabouço teórico entende que os reguladores e legisladores são naturalmente interessados em maximizar o bem-estar social, atuando sempre com o objetivo de corrigir "falhas de mercado". 
Por outro lado, Richard Posner (2004) afirma que, em mais de quinze anos de pesquisa empírica nos Estados Unidos, não restou demonstrado que a ampliação da regulação estatal tenha efetivamente produzido bons resultados, ficando claro que os objetivos declarados, relacionados a deficiências e externalidades do mercado não foram comprovados.

Além disso, a teoria acaba por não definir "qualquer intercâmbio ou mecanismo pelo qual uma concepção de interesse público é traduzida em ação legislativa”, conforme demonstra Posner (2004). Desta forma, não consegue objetivamente definir uma relação entre fatos e resultados, de maneira que as consequências possam ser vislumbradas e mensuradas sobre o prisma do interesse público e do bem comum.

De um ponto de vista crítico, o Estado como agente da atividade regulatória no exercício do seu poder de coerção, pode ser visualizado, segundo Stigler (2003), como a "principal fonte de recursos ou de ameaças a toda atividade econômica da sociedade. Com seu poder de proibir ou compelir, de tomar ou dar dinheiro, pode (e efetivamente o faz) ajudar ou prejudicar, seletivamente, um vasto número de indústrias".

Por seu lado, a Escola de Chicago, conhecida como econômica ou neoclássica, berço da teoria econômica da regulação, afirma que o objetivo da política regulatória é manter o livre mercado. Isso significa ampla concorrência e aperfeiçoamento dos processos normativos e administrativos, evitando assim que ocorram as "falhas de mercado", de acordo com Oliveira (2015), e as "falhas de governo" como se verá mais adiante.

As principais market failures são: o monopólio, caracterizado por um ambiente de negócios dominado por uma única empresa, que atua sem qualquer concorrência, estabelecendo unilateralmente o preço de produtos e serviços; as externalidades que podem ser positivas ou negativas e consistem em benefícios ou custos repassados para terceiros que não participam diretamente da atividade econômica; os bens coletivos, públicos ou não rivais, que são aqueles em que o consumo por um indivíduo não impede o consumo por outras pessoas, além de possibilitar a pessoas que não pagam pelo bem ou serviço, de fazerem uso dele, os free riders ou caroneiros (OLIVEIRA, 2015, p.51).

A teoria econômica da regulação afirma que o esforço individual produz uma alocação eficiente de recursos, sendo os objetivos atingidos plenamente mensuráveis, estabelecendo desta forma uma correlação entre interesses declarados e resultados alcançados, negando que a normatização carregue consigo um elemento de probidade e veracidade que dispense a avaliação sobre as suas consequências. 
Desde o primeiro estudo, conduzido por George Stigler em 1971, a teoria econômica da regulação vem ganhando espaço no ambiente acadêmico norte-americano, tendo por pressuposto "a análise do comportamento político a partir dos parâmetros da análise econômica. Políticos, assim como qualquer um de nós, são considerados maximizadores das suas próprias utilidades", segundo Peltzman (2004).

Cabe ressaltar que a ampliação regulatória, característica de um Estado intervencionista, pode produzir o que se conhece como "falha de governo", gerando alguns problemas que merecem atenção: a instituição de um "Estado babá" que age restringindo a liberdade dos indivíduos, estabelecendo uma relação paternalista entre o poder público e determinados grupos sociais; a captura da regulação pelos agentes econômicos regulados, em prejuízo dos cidadãos, afetando principalmente os consumidores, que se veem premidos pela formação de monopólios ou pela péssima qualidade dos serviços prestados; e a impossibilidade da execução de atividades econômicas em razão do grande número de restrições por parte do Estado, o que favorece a concentração de mercado, inibindo a concorrência e as atividades inovadoras, tão essenciais para o desenvolvimento econômico na modernidade.

Por esse motivo, torna-se útil estabelecer um ponto de equilíbrio, que admita a intervenção pública apenas no sentido de zelar pelas regras de concorrência, não criando normas em excesso, demonstrando claramente os objetivos, as ações, os resultados e os impactos na sociedade, sobre a ótica do custo-benefício da política regulatória.

\section{A REGULAÇÃO ECONÔMICA NO BRASIL}

No Brasil, o Estado intervém na economia de maneira direta, quando age como um agente econômico desenvolvendo atividades inerentes ao setor privado, ou indiretamente, a partir de uma política regulatória que sirva como indicativo para os investimentos da iniciativa privada conforme previsto na Constituição de $1988^{3}$.

Nas últimas décadas o país tem ampliado o seu arcabouço regulatório em razão do processo de privatização, que conduziu o controle de empresas estatais para grupos econômicos nacionais e estrangeiros, além da concessão de serviços públicos para empresas

\footnotetext{
${ }^{3}$ Art. 174. Como agente normativo e regulador da atividade econômica, o Estado exercerá, na forma da lei, as funções de fiscalização, incentivo e planejamento, sendo este determinante para o setor público e indicativo para o setor privado.
} 
privadas, rompendo com a lógica excludente entre Estado e iniciativa privada, que perdurava anteriormente, sem um ponto de equilíbrio entre aqueles, até então, caracterizados como opostos. Acerca do relacionamento do Estado com a economia, Moreira e Kato (2013, p. 223) analisam que:

\begin{abstract}
O relacionamento do Estado com a economia começou a ter características mais democráticas, estimuladoras, cooperativas e, até, substitutivas. Agora, a lógica do "ou-ou" passou a conviver com a do "e-e": Estado e iniciativa privada. A rigor, o que atualmente existe é o Estado integrado na economia, que ordinariamente atua no cotidiano das relações socioeconômicas. Ele não mais reprime e exclui, mas incentiva, influi e inclui.
\end{abstract}

O Estado passa a ser um coordenador-regulador do mercado, em consonância com o desenvolvimento econômico, agindo subsidiariamente sobre a ação dos agentes privados, exercendo o papel de principal mantenedor da segurança no ambiente de negócios, a partir da aprovação de uma eficiente regulação.

Não podemos olvidar que nossa cultura política, jurídica e econômica é adstrita ao curto espaço de tempo. Essa ausência de perspectiva estratégica do Estado, caracterizada por uma visão de médio e longo prazo, que sobreponha aos objetivos de cada governo, acaba restringindo o interesse do empresariado pelo mercado brasileiro, já que esses players buscam segurança jurídica e minimização de riscos para o aporte de investimentos.

É nesse cenário de gestão no ambiente de negócios que o Estado deve procurar desenvolver sua atividade regulatória, buscando sempre a redução da incerteza, objetivando tornar as disposições normativa claras, objetivas, reduzindo riscos e custos de transação, ampliando o acesso ao mercado e, por conseguinte, tornando a atividade econômica mais competitiva e concorrencial produzindo melhores serviços e produtos para usuários e consumidores.

Assim, a finalidade da atividade regulatória "tem a ver com a eficiência, sendo resultado da competição das forças no mercado entre agentes econômicos, para que permaneçam no mercado aqueles que estão aptos ao atendimento do interesse da coletividade" (MOREIRA; KATO, 2013).

Mas a regulação estatal não se exaure apenas na função de promover competição num cenário de livre mercado, é primordial a compreensão da intrínseca relação entre os agentes econômicos e as instituições responsáveis em financiar as atividades econômicas.

Cabe destacarmos que se após a Constituição de 1988 o aparelho estatal brasileiro afastou-se do exercício direto das atividades econômicas, assumindo um papel eminentemente 
regulador, no âmbito do sistema financeiro ocorreu justamente o oposto, pois ampliou a sua participação no mercado.

A maior parte do crédito disponível no país, essencial ao desenvolvimento do ambiente de negócios, advém de instituições criadas pelo Poder Público, tais como o Banco do Brasil, Caixa Econômica Federal, os bancos de fomentos regionais e, claro, aquele que se tornou a maior fonte de financiamento de longo prazo, o Banco Nacional de Desenvolvimento Econômico e Social (BNDES), que conta com um crescente aporte do tesouro, como sua principal fonte de recursos. Em 31 de dezembro de 2016 as fontes governamentais representavam $84,3 \%$ da estrutura de financiamento do $\mathrm{BNDES}^{4}$.

A partir dessa perspectiva, tão importante quanto compreender as regulações econômicas expedidas pelas agências públicas, será a necessária leitura da análise da regulação financeira e da concorrência, particularmente definidas pelo Banco Central do Brasil (BACEN); pela Comissão de Valores Mobiliários (CVM); e pelo Conselho Administrativo de Defesa Econômica - CADE, todas classificadas como autarquias em regime especial, que apresentam funções e autonomias muito semelhantes às agências reguladoras.

A atividade econômica e o correspondente financiamento são atividades simbióticas, que naturalmente não podem ser analisadas separadamente. Um cenário razoável de concorrência no âmbito dos mercados depende muito dessa compreensão. Não basta verificar os impactos decorrentes da normatização proveniente das agências estatais stricto senso, tais como a ANEEL, ANATEL, ANP, dentre outras; é imprescindível avaliarmos as consequências das prescrições provenientes das agências de regulação financeira sobre os agentes econômicos.

\section{AGÊNCIAS REGULADORAS NO BRASIL}

Diante do crash de 1929, os Estados Unidos, como resposta aos pressupostos liberais de não intervenção estatal no mercado, criaram a agência regulatória moderna, com a finalidade precípua de corrigir as "falhas de mercados" que deram origem àquela crise, evitando desta maneira que os fatos viessem a se repetir no futuro.

\footnotetext{
${ }^{4}$ Ver: http://www.bndes.gov.br/wps/portal/site/home/transparencia/fontes-de-recursos. Acesso em 07 de julho de 2017.
} 
O modelo norte-americano buscou especializar o controle das agências a partir da ampliação da discricionariedade técnica e da limitação do controle dos atos regulatórios por parte do poder judiciário, estando a autonomia administrativa sujeita ao controle pelos três Poderes, diante de um sistema de freios e contrapesos.

Inspiradas no modelo norte-americano foram instituídas, durante a década de 90, as agências reguladoras no Brasil. Essa opção pode ser compreendida a partir das mudanças decorrentes da Constituição de 1988 e da legislação posterior que indicavam uma maior liberalização econômica e sensível diminuição da participação do Estado na economia, a partir da abertura do mercado ao capital estrangeiro, da redução dos monopólios estatais e da aprovação da Lei n. 9.491/1997 que trata do Programa Nacional de Desestatização (PND).

Como entidades da administração indireta, as agências reguladoras apresentam características próprias que as diferenciam na estrutura organizacional do Estado, sendo criadas por leis específicas, com independência técnica e autonomia administrativa, já que, segundo Souto (2011, p. 1151):

[...] é preciso que a agência reguladora seja dotada de capacidade para acompanhar o mercado, cuja velocidade de funcionamento exige que a estrutura administrativa dedicada a fiscalizá-lo e a orientá-lo deva ser a mais ágil possível, sob pena de ser ineficiente e não se justificar sua existência.

Estas entidades possuem a capacidade de editar atos administrativos normativos, conhecido como poder normativo e deslegalização, desde que com respeito aos ditames legais inerentes à atividade regulada. A decisão deve atentar para requisitos técnicos, com o objetivo de impedir ou ao menos minimizar a influência política no processo regulatório. Nesse diapasão, sustenta Oliveira (2015, p. 152) que:

\footnotetext{
Com a deslegalização, opera-se uma verdadeira degradação da hierarquia normativa (descongelamento da classe normativa) de determinada matéria, que, por opção do próprio legislador, deixa de ser regulada por lei e passa a seara do ato administrativo normativo. A lei deslegalizadora não chega a determinar o conteúdo material da futura normatização administrativa, limitando-se a estabelecer standards e princípios que deverão ser respeitados na atividade administrativo-normativa.
}

Não podemos olvidar que, ao realizar o descongelamento de determinada matéria, a lei deslegalizadora atribui a agência o poder de editar atos administrativos com primazia sobre leis genéricas que tratem do assunto sobre sua esfera de regulação. 
Durante o julgamento da Ação Direta de Inconstitucionalidade (ADI) n. 4568/DF ${ }^{5}$ o ministro Luiz Fux, acompanhando a relatora ministra Carmen Lúcia, elencou no seu voto que, diante da "crise da lei", ou seja, do fato que a legislação não consegue acompanhar tempestivamente as mudanças sociais, as agências reguladoras independentes apresentam capacidade de resposta mais ágil e técnica, criando uma dinâmica diferente na relação entre os poderes executivo e legislativo, reconhecendo expressamente a aplicabilidade da teoria da lei deslegalizadora.

Por fim, assim como no modelo norte-americano, as agências brasileiras são controladas pelos três poderes. Existe um controle político prévio relacionado com a definição da estrutura e do objetivo da agência reguladora, mediante a apresentação do respectivo projeto de lei. Além disso, o poder executivo participa ativamente do processo de indicação e nomeação dos dirigentes das agências. O legislativo acompanha a edição de normas com vistas a evitar regulação dúplice e o Judiciário, em regra, atua corrigindo ilegalidades.

\section{A REGULAÇÃO NA TUTELA DA CONCORRÊNCIA}

Para compreendermos o papel da política regulatória na promoção e defesa da concorrência é importante analisar, primeiramente, os efeitos do monopólio sobre o mercado e também sobre os consumidores.

O monopólio do mercado, para fornecedores de produtos e serviços, é uma situação segura, invejável e valorizada, pois permite controle total sobre os preços e a quantidade de serviços ou produtos comercializados, liberando o monopolista para auferir lucros muito maiores do que aqueles que um agente econômico teria se tivesse que enfrentar um mercado concorrencial (MACKAAY; ROUSSEAU, 2015, p. 110).

Por outro lado, os consumidores acabam suportando o ônus do monopólio, já que muitos são preteridos pelo mercado, ao passo que outros pagam mais caro pelo serviço do que pagariam num regime de concorrência, transferindo uma parte maior da sua renda para o fornecedor.

Essa espécie de concentração, no âmbito da prestação de serviços de utilidade pública, é definida pela impossibilidade de concorrência na atividade econômica, já que as “empresas que os fornecem incorrem em situações de mercado, onde há economias de escala

\footnotetext{
${ }^{5}$ STF, ADI 4568/DF, Rel. Min. Carmem Lúcia, Tribunal Pleno, DJ n. 65, de 30/03/2012.
} 
tais, que apenas uma única empresa é capaz de suprir a demanda pelo produto ou serviço, com custos inferiores aos que ocorreriam, se houvesse mais de uma empresa atuando no mercado" (BASSO e SILVA, 2000, p. 69).

Diante desse cenário, a percepção econômica da concorrência admite duas interpretações. A representada pela escola neoclássica que adota a concepção que a concorrência é estática, caracterizada por um mercado que conta com "numerosos fornecedores que oferecem um produto relativamente homogêneo a uma clientela numerosa e bem informada, segundo o qual o preço tende a se estabelecer no equilíbrio" (MACKAAY; ROUSSEAU, 2015, p. 112).

Em outro sentido, a escola dinâmica da concorrência, preconizada por Schumpeter, Misses, Hayek, dentre outros, preconiza que o desenvolvimento é muito mais relacionado com desequilíbrios do que com o equilíbrio do mercado. O fator que causa inquietação nesse sistema é a oferta de novos produtos, decorrente de um intenso processo de inovação, como alertado por Mackaay e Rousseau (2015, p. 112):

O inovador propõe o novo produto a uma clientela até então fiel ao produto
tradicional. Deve convencer os consumidores de que, pelo preço proposto, o
produto, com caracterísiticas particulares, pode substituir, com vantagem, aqueles
tradicionais e disponíveis. Se o produto for, efetivamente, melhor, alguns
consumidores alterarão, imediatamente, sua escolha; outros aguardarão que a nova
fórmula seja aprovada para, então, mudarem. Os fornecedores de produtos mais
tradicionais perderão clientela e lucros. Decorrido algum tempo, seguirão o exemplo
do inovador e oferecerão, também, a nova fórmula, ou, de sua parte, envidarão a
busca por inovação, proporão produto novo cuja atração supere, desde logo, a do
produto inovador. E assim sucessivamente.

Vista sobre o aspecto dinâmico a concorrência é conceituada como um contínuo processo nos quais empreendedores, recorrendo a inúmeras estratégias, como a inovação, por exemplo, tentam realizar combinações entre clientes e produtos que lhes ofereçam uma vantagem competitiva sobre os concorrentes. Isso gera instabilidade, mas é essa instabilidade que faz com que o capitalismo, ancorado na concorrência e na inovação, sobreviva com o passar dos séculos, permitindo desenvolvimento econômico para muitas sociedades.

Desta forma, a concorrência permite não apenas que o mercado permaneça em constante mutação, admitindo a inserção de novos competidores que alteram o próprio mercado com novos produtos ou serviços inovadores, mas principalmente uma relação mais equilibrada entre poder político e liberdade econômica, segundo a análise de Friedman e Friedman (Kindle, 204-205). 
A liberdade econômica é uma condição essencial para a liberdade política. Ao possibilitar que as pessoas cooperem umas com as outras sem coerção nem comando central, tal liberdade reduz a área sobre a qual é exercido o poder político. Além disso, por dispersar o poder, a economia de mercado proporciona uma compensação para qualquer concentração de poder político que possa surgir. A combinação de poder econômico e político nas mesmas mãos é uma receita segura para a tirania.

E em face disso, a intervenção estatal, ou seja, a política regulatória deve ser instituída, dentre outras possibilidades, principalmente para garantir e proteger um livre mercado, possibilitando que vários ofertantes participem do ambiente de negócios, dinamizando as alternativas de oferta de produtos e serviços para usuários e consumidores.

A mudança de paradigma com relação à abordagem de mercado sobre o serviço público no ordenamento jurídico brasileiro deve muito à aproximação teórica entre o direito francês, que influenciou o Brasil a partir do estabelecimento de uma separação entre as atividades privadas e aquelas que são de titularidade do poder público, mas exercidas pelos particulares mediante delegação ou concessão; e as public utilities, como são conhecidas na tradição norte-americana as atividades conduzidas pela iniciativa privada, mas sujeitas a controles e regulamentação pelo poder público (OLIVEIRA, 2015, p. 161-162). Esse sistema híbrido abraça a premissa de que a concorrência é essencial para a melhoria da qualidade na prestação do serviço público para os usuários.

Uma política regulatória será considerada “melhor", não apenas se for mais eficiente, com menor custo-benefício, mas também se atentar para a liberdade de mercado, ampliando o ambiente de negócios para novos empreendedores, fomentando a inovação e produzindo mais vantagens para usuários de serviços públicos.

Assim a Better Regulation constitui-se numa forma de raciocínio devidamente estruturado que serve de base para uma política regulatória e também para a governança da regulação. Em tese, busca durante o processo de regulação analisar variáveis que possibilitem um equilíbrio entre as "falhas de mercado" e o livre mercado. Para esse incremento de qualidade deve fazer uso de ferramentas de avaliação de impacto regulatório, que permitam medidas como, a melhoria da transparência; a redução da burocracia; a utilização sempre que possível de recursos não regulatórios; a emissão de regras de execução; a estipulação cláusulas de caducidade para evitar que a regulação se torne obsoleta; e a análise periódica da normatização expedida (DUNNE, Kindle, p. 162). 


\section{ANÁlISE ECONÔMICA DO DIREITO E A ANÁliSE DE IMPACTO REGULATÓRIO}

A modernidade apresenta para a ciência jurídica uma série de desafios relacionados às crescentes e complexas demandas sociais. $\mathrm{O}$ pensamento jurídico hodierno não pode se limitar apenas a uma leitura de como deve ser o direito, desprovido de qualquer senso crítico, sob pena de se tornar mais uma ferramenta técnica para a manutenção do status quo, ao invés de uma ciência capaz de cambiar as relações econômicas e de poder, na busca da eficiência e do bem-estar social.

A aproximação entre direito e economia é desejável não só porque torna a avaliação mais descomplicada, mas também porque ajuda a compreender a verdadeira influência das normas jurídicas sobre o comportamento dos indivíduos e dos grupos de interesse, auxiliando no momento da tomada de decisão sobre uma política pública ou mesmo na fundamentação de uma decisão judicial.

Desta forma, estruturar processos que dificultem a escolha de alternativas precárias, restringindo a discricionariedade dos decisores políticos, a partir de critérios de custobenefício e de estímulo à racionalidade na tomada de decisão, minimizam consideravelmente a possibilidade de que tenhamos decisões ruins, tendenciosas ou até mesmo irracionais em matéria de regulação estatal (CHOI; PRITCHARD, 2003, p. 36).

Nesse diapasão, a AED parte dos conceitos da teoria microeconomia para explicar as consequências do processo decisório. Shavell (2004, p.1-2) aponta dois tipos de questionamentos, acerca das normas jurídicas, que necessitam de resposta por parte da Análise Econômica do Direito. Uma análise descritiva, relacionada com o comportamento dos indivíduos, seus interesses e as consequências dos seus atos; e uma análise normativa relacionada com a eficiência e com o bem-estar gerado pelo sistema normativo, nos seguintes termos:

Análisis descriptivo. La incorporacion de las cuestiones descriptivas en los modelos
suele implicar la consideración de los agentes como seres "racionales". Es decir,
tienen em cuenta el futuro y se comportan tratando de hacer máxima su utilidad
esperada. Uma vez caracterizados los indivíduos como agentes racionales, podemos
determinar la influencia ejercida por las normas legales sobre su comportamiento.
Dicha influencia puede determinarse con precisión en el mundo de os modelos,
porque se explicitan todos los supuestos relevantes acerca de los deseos de los
indivíduos, sus conecimientos, capacidades y entorno [...] Análisis normativo. La
evaluación de las políticas sociales, y por tanto de las normas jurídicas, há de
llevarse a cabo tomando como referencia uma determinada medida de bienestar
social. Uma norma jurídica será superior a outra segundo si como resultado de 
la primera norma se deriva um nível más alto de bienestar social de acuerdo com la medición estabelecida. (Grifo nosso)

Cumpre destacar que as obras sobre AED na língua inglesa comumente não se preocupam em explicar a metodologia utilizada para, diante de situações concretas, estabelecer quando uma regulação ou decisão é eficiente e maximiza o bem-estar social. A questão do método é objeto de estudo principalmente pelos autores alemães e holandeses, que estabelecem três objetivos para a análise econômica do direito, sob uma perspectiva consequencialista: análise dos efeitos; análise descritiva da coerência das regras; e análise normativa do caráter desejável das soluções incorporadas nas regras (MACKAAY e ROUSSEAU, 2011, p. 665-666).

A eficiência, sob a lógica da AED, está relacionada com o aumento do bem-estar que ela promove. Nesse sentido, destacam-se os conceitos de eficiência econômica de Pareto e Kaldor-Hicks.

Uma política regulatória será eficiente, sobre o prisma de Pareto, quando ocorre a melhora da situação de alguns agentes sem que nenhum outro seja prejudicado. Em síntese, não há perda, afinal todos estão em situação melhor ou pelo menos igual àquela em que se encontravam antes da implementação da regulação. É uma visão restrita da eficiência.

Um conceito mais amplo de eficiência é o de Kaldor-Hicks, que combina custos e benefícios, de tal forma que se os benefícios totais forem maiores do que os custos totais, a política regulatória pode ser considerada eficiente. Neste caso, mais realista, já que enquanto alguns agentes econômicos ganham outros perdem.

Sustenta Souto (2011, p.1144) sobre a ponderação entre custos e benefícios na intervenção:

Esse é o papel da regulação, isto é, testar, tecnicamente, a ponderação entre custos e benefícios na intervenção de um determinado segmento, de modo que a norma só vai ser eficiente se os benefícios forem iguais ou maiores que os custos envolvidos na sua implementação, que envolve uma restrição de liberdade. Somente com o cumprimento desse dever jurídico é que se afasta a responsabilização da agência.

Nesse espaço de busca da eficiência, que pondera durante o processo da tomada de decisão os custos e benefícios da atividade regulatória, Posner (2010, p. 08) afirma que AED tem muito a contribuir, pois além de apresentar aspectos descritivos e normativos, explicando e prevendo o comportamento dos indivíduos e grupos que participam do sistema, interpreta a doutrina, os procedimentos e as instituições que fazem parte do ordenamento. Para o autor, a AED também exerce papel importante no aperfeiçoamento do modelo jurídico, demonstrando 
as consequências da legislação em vigência, dos projetos de leis e, inclusive, das propostas regulatórias.

Assim, com o objetivo de reduzir assimetrias informacionais e melhorar a qualidade da atividade estatal na busca da melhoria das práticas regulatórias, com vistas a mais eficiência, bem-estar social e transparência, é que acontece a institucionalização da Análise de Impacto Regulatório (AIR), sendo precursores nesse processo as administrações Reagan nos Estados Unidos e Thatcher na Inglaterra.

O Brasil caminha nesse sentido, mas ainda carece de uma institucionalização da ferramenta de análise em comento. Cabe ressaltar que uma regulação eficiente por parte das agências estatais provavelmente conduzirá o país para um patamar mais competitivo no cenário econômico mundial, atraindo investimentos, desenvolvendo negócios e gerando mais empregos.

Não podemos olvidar que existem questionamentos relacionados à institucionalização da AIR, ancorados basicamente no fato de que, por ser baseada na maximização do bem-estar social a partir da leitura econômica, tal ferramenta desprezaria questões éticas relacionadas como a vida e o meio ambiente, sendo que em muitos casos, na visão desses críticos, a análise fundada no custo benefício serviria mais para complicar do que para esclarecer questões que envolvessem valores ${ }^{6}$.

Já os defensores afirmam que devem ser ressaltadas as virtudes, como uma maior racionalidade na tomada de decisão e também com o ganho qualitativo nos resultados. A AIR possibilita a definição de prioridades, tendo em vista a escassez de recursos, além de visualizar com antecedência uma rota segura para superar obstáculos à eficiência da regulação, a partir da análise e do debate.

Sunstein (1999, p. 39) defende que é possível resolver questões difíceis em direito ou na política, que envolva atores com diferentes visões de mundo, a partir da análise de custobenefício, "A prime purpose of the approach is to ensure more in the way of reflection; cost-

\footnotetext{
${ }^{6}$ There are hard question to be answered about protection of hum health and the environment, and ther are many useful insights about these questions fomr the field of economics. But there is no reason to think that the right answers will emerge from the strange process of assigning dollar values to human life, human health, and nature itself, adn then crunching the numbers. Indeed, in pursuinhg this approach, forma costa-benefit analysis often hurts more than it helps: it muddies rather than clarifies fundamental clashes about values. (Cf. ACKERMAN, Frank; HEINZERLING, Lisa. Priceless: on Knowing the Price of Everything and the Value of Nothing. Nova York: New Press, 2004, p. 9.)
} 
benefit analysis, as understood here, is a guarantee of greater deliberation, not an obstacle to $i t^{\prime \prime}$.

Assim sendo, a AIR é um meio auxiliar à tomada de decisão que mensura os custos, os benefícios, os riscos e os resultados da atividade regulatória, definindo qual política é capaz de ampliar a maximização do bem-estar social, ou no caso específico deste artigo, proteger e incentivar a concorrência e fomentar a inovação, com vistas à melhoria do desenvolvimento econômico.

O processo de avaliação da AIR apresenta três fases, como destaca Oliveira (2015, p. 270): a inicial ou expositiva, na qual os objetivos e os resultados esperados com a nova regulação, ou a que já existe, devem ser demonstrados; a intermediária que trata da ampla participação dos regulados, empreendedores, empresários, usuários de serviços públicos e consumidores, para o estabelecimento de critérios de julgamento para a escolha da melhor medida regulatória, inclusive com a ponderação de valores para as possíveis soluções apresentadas; e uma fase decisória com a implementação da nova regulação ou a revisão da regulação já existente.

Ampliamos essa perspectiva, tendo em vista que se trata de um processo cíclico, que na nossa visão não se exaure com a simples entrada em vigor da nova regulamentação, existindo a necessidade de monitoramento constante da correlação entre objetivos declarados e resultados alcançados pela política regulatória no curto, médio e longo prazo.

A AIR apresenta, dentre várias abordagens, duas principais metodologias de aferição da intensidade e qualidade da regulação. São elas a Análise de Custo-Benefício (ACB) e a Análise de Custo-Efetividade (ACE).

A ACB informa que a regulação deve avaliar todos os custos e benefícios, tangíveis e intangíveis, que dizem respeito à proposta. Os custos tangíveis são de fácil mensuração, ao passo que os intangíveis, por apresentarem aspectos subjetivos, são mais complexos e difíceis de serem ponderados, além de envolver uma série de questionamentos relacionados com o comportamento humano.

Na prática, a política regulatória deve, sempre que possível, buscar uma ação pedagógica por intermédio de medidas informacionais e educativas, demonstrando as alternativas que foram negligenciadas, para só depois partir para uma regulação fundada numa análise de custo-benefício. Não podemos esquecer que a atividade regulatória não é uma

\footnotetext{
${ }^{7}$ Tradução livre: "O objetivo primordial da abordagem é garantir mais o caminho da reflexão; a análise de custo benefício, conforme entendido aqui, é garantia de maior deliberação, não um obstáculo a isso".
} 
atividade livre de custos, mas sim, extremamente impactante na forma de custos de transação para a iniciativa privada.

Sunstein (Kindle, 3051-3072) apresenta Four Ways to Humanize the Regulatory State, ou seja, quatro formas de humanizar a análise de custo-benefício, naquilo que denominou como um modelo de álgebra política: em primeiro lugar, custos e benefícios não são abstrações aritméticas, apresentam muito mais do que simples números, são esforços destinados a capturar bens qualitativamente diversos e para promover compromissos sensíveis entre eles; também não se pode olvidar que alguns valores são difíceis de quantificar, representando sérios desafios para análise custo-benefício, não se podendo perder de vista, desta feita, os valores que são quantificáveis e servem de base para o planejamento das políticas regulatórias; outro ponto fundamental é levar em consideração não apenas as ações racionais humanas (homo economicus) para se estabelecer uma regulação eficiente, mas também o fato de que costumeiramente as pessoas fazem uso de atalhos mentais na avaliação de riscos e tomam decisões intuitivas, muitas das vezes erradas ou ineficientes; e, por fim, o processo de regulação deve coletar e buscar dados e informações de maneira dispersa, ampliando o debate para o maior número possível de interessados, tanto do setor público quanto do privado.

De outra forma, a ACE é uma abordagem sobre a regulação estatal que é caracterizada pela prévia definição dos indicadores e metas regulatórias, que devem sempre obedecer à alternativa que representa o menor custo, evitando assim debates sobre qual a melhor escolha quando se está diante de benefícios e custos que não são passíveis de precificação (OLIVEIRA, 2015).

Como já foi dito anteriormente, a AIR é largamente utilizada em vários países do mundo, em especial naqueles que fazem parte da Organização para a Cooperação e Desenvolvimento Econômico (OCDE).

No Brasil, o instituto vem sendo desenvolvido pelas agências reguladoras a partir do "Programa de Fortalecimento da Capacidade Institucional para a Gestão da Regulação", instituído pelo Decreto n. 6.062, de 16 de março de 2007, que define os objetivos ${ }^{8}$ e o modelo de governança do programa.

\footnotetext{
${ }^{8}$ Art. $2^{\circ}$ O PRO-REG deverá contemplar a formulação e implementação de medidas integradas que objetivem: I - fortalecer o sistema regulatório de modo a facilitar o pleno exercício de funções por parte de todos os atores; II - fortalecer a capacidade de formulação e análise de políticas públicas em setores regulados; III - a melhoria da coordenação e do alinhamento estratégico entre políticas setoriais e processo regulatório; IV - o fortalecimento da autonomia, transparência e desempenho das agências reguladoras; e
} 
Exemplificativamente podemos citar a Agência Nacional de Energia Elétrica (ANEEL), que por intermédio da Resolução Normativa n. 540, de 12 de março, tornou a AIR obrigatória antes da expedição de qualquer ato regulatório ${ }^{9}$, definindo uma série de questionamentos sobre o problema que se quer resolver; o público alvo impactado com a medida; as justificativas para a intervenção; os objetivos a serem alcançados; as alternativas disponíveis, inclusive a opção pela não regulamentação; a análise de custo-benefício propriamente dita, levando-se em consideração os aspectos financeiros e não financeiros; além da comparação entre a nova alternativa e a regulamentação já existente; por fim, o monitoramento constante dos resultados alcançados.

Diante do que foi exposto, existe a necessidade de institucionalização não apenas da AIR, mas da lógica consequencialista, que trata da eficiência e da eficácia na aplicação dos recursos públicos e de certa forma da interpretação do próprio direito, ainda muito arraigado em argumentos abstratos que não mensuram os impactos das decisões, fato extremamente grave dentro de um cenário de recursos cada vez mais escassos.

Talvez com esse intuito tenha sido elaborado projeto de lei pelos juristas Carlos Ari Sundfeld e Floriano Marques de Azevedo Neto ${ }^{10}$, ainda tramitando no Congresso Nacional, que trata da segurança jurídica e eficiência na criação e aplicação do direito público nas esferas administrativa, judicial e de controle.

\section{CONSIDERAÇÕES FINAIS}

Após a reforma administrativa na década de 90, o Estado brasileiro passou a exercer a função de coordenador-regulador na seara econômica, afastando-se do exercício de atividades privadas e até mesmo da prestação direta de serviços públicos.

As agências reguladoras, que apresentam características próprias, como independência e autonomia administrativa, foram as entidades incumbidas não apenas de editar os atos administrativos regulatórios, mas também de executá-los e físcalizá-los.

V - o desenvolvimento e aperfeiçoamento de mecanismos para o exercício do controle social e transparência no âmbito do processo regulatório.

${ }^{9}$ Ver. Resolução Normativa n. 540, de 12 de março de 2013. Disponível em: < http://www2.aneel.gov.br/cedoc/ren2013540.pdf>. Acesso em 20 de julho de 2017.

${ }^{10}$ Ver. Projeto de lei n. 349, de 2015, que inclui na Lei de Introdução às Normas do Direito Brasileiro (Decretolei n. 4.657, de 1942), disposições sobre segurança jurídica e eficiência na criação e aplicação do direito público. Disponível em: <http://www25.senado.leg.br/web/atividade/materias/-/materia/121664>. Acesso em 10 Jul 2017. 
Nesse diapasão, a qualidade da regulação estatal, uma das formas de intervenção na economia, assume diante do atual cenário competitivo internacional, um relevante papel no fomento à concorrência, inovação e ao próprio desenvolvimento econômico do país.

Por outro lado, a tecnologia e a inovação vêm alterando constantemente o mercado, trazendo importantes mudanças na regulação estatal, que já não consegue acompanhar a realidade social com a velocidade necessária. Em face disso, percebe-se que mesmo naqueles nichos de negócios caracterizados tradicionalmente como "monopólios naturais", a exemplo de alguns serviços de utilidade pública, existe a possibilidade de concorrência.

Diante desse universo infindável de normatizações, leis, decretos, resoluções, portarias, dentre outros, que literalmente paralisam o país em razão da total insegurança jurídica, racionalizar a regulação estabelecendo metas objetivas e mensuráveis, é uma alternativa válida para a eficiência da administração pública, que atualmente gasta páginas e mais páginas numa retórica que não apresenta finalidade prática nenhuma. Estamos diante do paradigma da qualidade e não mais da quantidade em matéria de regulação estatal.

Políticas regulatórias mais eficientes, que respeitem a relação custo-benefício, devidamente planejadas, executadas e avaliadas, ampliando a concorrência e o aumento do bem-estar individual, são uma boa alternativa de gestão nesses tempos de crise, podendo servir para estimular a retomada do desenvolvimento econômico no Brasil.

$\mathrm{O}$ instrumento para fazer esse monitoramento e avaliação da política regulatória, capaz de avaliar custos e benefícios, tangíveis e intangíveis, é a Análise de Impacto Regulatório (AIR). Essa ferramenta é largamente utilizada no cenário internacional e no Brasil já começa a ser institucionalizada em algumas agências reguladoras, tais como a ANEEL.

\section{REFERÊNCIAS}

ACKERMAN, Frank; HEINZERLING, Lisa. Priceless: on Knowing the Price of Everything and the Value of Nothing. Nova York: New Press, 2004.

BATISTA, Patrícia; KELLER, Clara I. Por que, quando e como regular as novas tecnologias? Os desafios trazidos pelas inovações disruptivas. Revista de Direito Administrativo, Rio de Janeiro, v. 273, p. 123-163, set./dez. 2016.

BASSO, Leonardo F. C.; SILVA, Marcelo R. Reflexões sobre a regulamentação. Revista de Administração Contemporânea. v. 4, n. 2, Maio/Ago. 2000: 67-85. 
CAMPOS, Humberto A. Falhas de mercado e falhas de governo: uma revisão da literatura sobre regulação economia. Dir., Pol. Pub. e Mundial., Brasília, v. 5, n.2, p. 341379, jul/dez. 2008.

CARDOZO, José E. M.; QUEIROZ, João E. L.; SANTOS, Márcia W. B. (coords). Direito Administrativo Econômico. São Paulo: Atlas, 2011.

CORTEZ, Nathan. Regulating Disruptive Innovation. Berkeley Technology Law Jornal. Berkeley, n. 29, p. 175-228.

CHOI, Stephen. J; PRITCHARD. Adam C. Behavioral Economics and the SEC. Stan. L. Rev. 56, no. 1 (2003): 1-73.

DUNNE, Niamh. Competition Law and Economic Regulation: Making and Managing Markets. Cambridge University Press. Edição do Kindle.

FRIEDMAN, Milton; FRIEDMAN, Rose. Livre para escolher: Uma reflexão sobre a relação entre liberdade e economia. Editora Record. Edição do Kindle.

KIRKPATRICK, Colin; PARKER, David (coords.). Regulatory Impact Assessment: Towards Better Regulation? Massachusetts: Edward Elgar, 2007.

MACKAAY, Ejan; ROUSSEAU, Stéphane. Análise Econômica do Direito. 2. Ed. Tradução Rachel Sztajn. São Paulo: Atlas, 2015.

OLIVEIRA, Rafael C. R. Novo Perfil da Regulação Estatal: Administração Pública de Resultados e Análise de Impacto Regulatório. Rio de Janeiro: Forense: 2015.

MATTOS, Paulo (coord). Regulação econômica e democracia: o debate norte-americano. São Paulo: Editora 34, 2004.

PELTZMAN, Sam. A teoria econômica da regulação depois de uma década de desregulação. In: MATTOS, Paulo (coord). Regulação econômica e democracia: o debate norte-americano. São Paulo: Editora 34, 2004.

POSNER, Richard A. Teorias da regulação econômica. In: MATTOS, Paulo (coord). Regulação econômica e democracia: o debate norte-americano. São Paulo: Editora 34, 2004.

POSNER, Richard. Fronteiras da teoria do direito. São Paulo: Martins Fontes, 2010.

SALGADO, Lucia H. Análise de impacto regulatório: uma abordagem exploratória. Texto para discussão n. 1463. Brasília: IPEA, 2010, p.10. Disponível em: <https://works.bepress.com/lucia_salgado/15/>. Acesso em 07 Jul 2017

SHAVELL, Steven. Fundamentos del análisis económico del direito. Madrid: CERASA, 2004. 
SOUTO, Marcos J. V. Agências reguladoras e entidades similares. In: CARDOZO, José E. M.; QUEIROZ, João E. L.; SANTOS, Márcia W. B. Direito Administrativo Econômico. São Paulo: Atlas, 2011.

STIGLER, George J. A teoria da regulação econômica. In: MATTOS, Paulo (coord). Regulação econômica e democracia: o debate norte-americano. São Paulo: Editora 34, 2004.

SUNSTEIN, Cass R. After the rights revolution. Cambridge: Harvard University Press, 1993.

Cognition and Cost-Benefit Analysis. John M. Olin Program in Law and Economics Working Paper No. 85, 1999.

Valuing Life: Humanizing the Regulatory State. University of Chicago Press. Edição do Kindle.

REGULATORY IMPACT ANALYSIS: BEST PRATICES IN OECD COUNTRIES, 1997. Disponível em: <https://www.oecd.org/regreform/regulatory-policy/35258828.pdf>. Acesso em: 05 Jul. 2017.

ROCHA, Fábio A. (coord) Temas Relevantes de Direito de Energia - Tomo I. Rio de Janeiro: Synergia, 2012.

Temas Relevantes de Direito de Energia - Tomo II. Rio de Janeiro: Synergia, 2013.

SMITH, Vernon L. Regulatory Reform in the Electric Power Industry. Regulation, 1 (1996): pp. 33-46. Web.

TAPSCOTT, Don; WILlIAMS, Anthony D. MacroWikinomics: New Solutions for a Connected Planet. Atlantic Books. Edição do Kindle. 